\title{
The Independent Scholar as Change Agent: The Case of Foreign Language Advocacy
}

\author{
Kathleen Stein-Smith \\ Fairleigh Dickinson University, Metropolitan Campus, Teaneck, NJ, USA
}

\begin{abstract}
There is a foreign language deficit in the United States, and the independent scholar, with both motivation and expertise, can play a significant role as a foreign language advocate, able to bridge the gap between communities and academia, and to operate with relatively more freedom that many language stakeholders, embedded in educational institutions and business environments. The skills set, or core competencies, of the independent scholar-advocate, the importance of online communities and advocacy, and agility in effective advocacy are examined. The case of foreign language advocacy could be generalized to include many other areas where the independent scholar can play a significant role as change agent for the greater good in our society and in our world
\end{abstract}

Index Terms - foreign language learning, bilingualism, advocacy, independent scholar

\section{INTRODUCTION}

Independent scholars are everywhere -- around the world, and just down the street, representing a broad array of disciplinary knowledge. By definition, they are resourceful and motivated, pursuing research and scholarship outside of traditional academia (Gross, 1982). However, while independent scholars may be located anywhere and may have varied educational profiles, they are also relatively rare, with only $2 \%$ of Americans holding a doctoral degree, and only 13\% holding any degree beyond the undergraduate level (Wilson, 2017; America Counts, 2019). This combination of having a level of education and expertise held only by a small minority, along with relative freedom, often confers a sense of social responsibility -- and even solidarity -- in terms of using education to make the world a better place.

The independent scholar has the education and expertise, the motivation, and -- most importantly -- the independence, or freedom, to be a change agent, or effective advocate, for an idea or cause. The independent scholar is generally also firmly embedded in the day-to-day world of work and community rather than within academia, and this supports the unique perspective of a scholar, or insider, along with that of an intentional outsider, on educational and other issues. However, there is relatively little discussion of this role of the independent scholar in scholarly or academic literature, or in the public conversation.

This may stem from the identity, or the image, of the independent scholar, in the public conversation, in the media, and on social media. It may be that the independent scholar is considered to be isolated from the world, solitary in the pursuit of research, and unconcerned about the issues of the day. However, nothing is farther from the truth. Independent scholars are often engaged with complex issues, both global and local. Many are tech-savvy, online, and passionate about their discipline and about our world.

The skills set of the independent scholar, bridging the gap between academic and scholarly research and real-world issues, can be the ideal combination for an effective change agent, comfortable with participating in data-driven research and discussions and with working either alone, or in collaborative partnerships including non-academic stakeholders.

\section{EDUCATION, RESPONSIBILITY, AND SOLIDARITY}

Education is often considered both a process and the body of knowledge resulting from that process (MerriamWebster, n.d), and the educated person has often been described in terms of responsibility and solidarity. As Nelson Mandela said, "education is the most powerful weapon which you can use to change the world (Ratcliffe, 2017). As Martin Luther King wrote, "We must remember that intelligence is not enough. Intelligence plus character-that is the goal of true education. The complete education gives one not only power of concentration, but worthy objectives upon which to concentrate. The broad education will, therefore, transmit to one not only the accumulated knowledge of the race but also the accumulated experience of social living (King, 1947).

Education matters, and its importance has been highlighted in more recent years by the inclusion of education in both the United Nation's Millennium Development Goals and the Sustainable Development Goals, most recently with Quality Education as Goal 4, among the 17 Sustainable Development Goals, where it is described as "one of the most powerful and proven vehicles for sustainable development" (UNDP, 2020). In the US, then-Secretary of Education Arne Duncan urged graduating college students to use their "considerable talents and skills not just to climb the ladder of personal advancement but to make the world a better place" (USDOE, 2015). 
Education has many purposes. When education is discussed, it is often in terms of the development of cognitive, academic, and pre-professional skills, and among these, critical thinking and the ability to reason and to communicate are often mentioned (NEA, web, 2019). While this is certainly true, education serves a goal that transcends the individual, bringing with it the responsibility to bring the skills, mindset, and worldview gained through education to the examination of issues both global and local, in the tradition of leaving the world a better place. Often university mission statements include concepts of the enlightenment and empowerment of education with the goals of service and social responsibility (UI\&U, web, n.d.). Those who have education have responsibility to use that education through solidarity with their community, either local or global, for the greater good.

It is also important to bear in mind that in the US, relatively few have advanced degrees -- in the US, nearly $2 \%$ have a doctoral degree, and only $13.1 \%$ have and degree beyond the undergraduate level. In the OECD countries, just 1.1\% have a doctoral degree (Wilson, 2017; America Counts, 2019; Hutt, 2019), making education a privilege with concurrent responsibilities. While it is possible to take education for granted and to assume that it confers no additional social responsibility, in addition to the benefits of education to the individual and to the society as a whole in terms of progress and innovation, those who are educated, in the spirit of solidarity, have a social responsibility to society as a whole.

The purpose of education is operationalized by the curriculum, but in the case of multilingualism, while approximately half of the world population is multilingual (Grosjean, 2010, 2020), not only are English-speaking Americans in the US unlikely to be able to hold a conversation in a language other than English (McComb, 2001), but US students tend to begin language study later than students in many other country (Devlin, 2015; Devlin, 2018), if at all, and the opportunity for foreign language learning is actually decreasing(AMACAD, 2017; Stein-Smith, 2019).

\section{THE FREEDOM AND RESPONSIBILITY OF THE INDEPENDENT SCHOLAR}

There is also the question of social responsibility for the independent scholar. While some independent scholars may simply cherish their freedom to devote themselves wholeheartedly to the pursuit of their research without the constraints of a full-time work life or tenure-track position, which can include creative constraints of publication in a specific group of scholarly peer-reviewed journals, or participation in specific academic organizations in their discipline, and presentations at the conferences and other meetings of said organizations, as well as time constraints of participation in numerous meetings and other campus activities, many are actively engaged in the public conversation as public intellectuals addressing a wide variety of issues.

Interdisciplinarity, essential to many areas of research and beneficial to many more, is often not encouraged as the department structure of the traditional US university and many others around the world, is often relatively silo-ized among traditional disciplines. Interdisciplinary collaborations, research, and publications are often not recognized in evaluations and decisions on rank and tenure, generally made in function of a specific home department. The independent scholar, on the other hand, is freer to examine complex issues through the lenses of more than one relevant disciplinary perspective and to collaborate not only with fellow academics in the same discipline, but also with scholars across the disciplines, including not only traditional academics, but also other independent scholars, experts from business and industry, as well as other thought leaders and influencers.

Publication is another area where the independent scholar can choose among scholarly peer-reviewed journals in a specific field, across the disciplines, or those with an interdisciplinary perspective. Beyond the scholarly journal, the independent scholar has a greater opportunity to publish in practitioner publications, as well as on blogs, social media, in opinion and op-ed pieces, etc., and to speak out as a public intellectual.

However, as with all freedom, this relative freedom of the independent scholar comes with responsibility. The first responsibility, shared by all who have had the privilege of education, is to make and to leave the world a better place. So, too, must the independent scholar be a research and scholar with a sense of social responsibility, and the specific research, writing, and action pathway varies for each, depending on the nature of the scholar's research and on the core values of each individual.

It is also important to consider the role and significance of the independent scholar in terms of scholarly professional engagement in both social and pragmatic terms. While the independent scholar may freely chose to participate -- or not -- in the relevant scholarly and professional associations, those who do choose to attend and to present at conferences, to serve on committees and in other leadership positions, and to publish in these association journals, need to consider not only their own research, writing, and engagement as individuals, but also the impact of their participation on the career professionals -- teachers and scholars -- in these associations. In other words, the independent scholar needs to make a contribution to the advancement of the field in alignment with their participation profile. As every leadership position, publication, presentation, or other engagement of an independent scholar inevitably fills a slot that might otherwise be occupied by a teacher/scholar embedded in an educational institution, the independent scholar needs to be mindful of the obligation to contribute and to work for the greater good, particularly in ways that career professionals may not be able to do, or that may be detrimental to their careers.

While these possibilities and potential contributions to the conversation are important, they are seldom mentioned in the literature. 


\section{The IndePendent Scholar as Change Agent And Foreign Language Advocate}

While K-12 teachers and postsecondary faculty can certainly act in a number of important ways to advance the scholarly and public conversation and to advocate for their students and their programs, it is important to recognize that the independent scholar, with both the responsibility to act and the relative freedom to act without deleterious consequences, can play a significant role as change agent.

While often be viewed as an outsider, unaffiliated with a program or institution, the independent scholar can play a significant role both in bringing an area of research or a discipline to the scholarly and public conversation and in advocacy as a change agent, both promoting an area of interest and defending programs and entities at risk. Independent scholars can draw inspiration from, and partner with, embedded scholars and teachers and can use their professional engagement to advance their cause with fewer obligations and constraints, limited only by the imagination and creativity of each one.

The effectiveness of the independent scholar as change agent is enhanced by the fact that the advocacy of the independent scholar is generally not related in any way to job security or to professional advancement, altruistic rather than based in self-interest.

Advocacy, defined as support and défense (AATF, web, n.d.), is an area where the independent scholar can truly work for the greater good -- while the benefits of language learning and bilingualism have been clearly demonstrated, the opportunity for foreign language learning as diminished at all levels in the US. The need for language learning in the US, and for effective advocacy is an example of the idea-advocacy matrix, where change is driven by both the quality of the idea, and by effective advocacy and advocates (Daly, 2011).

In order to serve as an effective advocate for foreign language learning and use, the independent scholar can engage in all of the activities open to scholars and educators embedded in schools, colleges, and universities, including participation in and service to the professional associations. However, the unique role of the independent scholar transcends the classroom and the educational institution, and real contribution of the independent scholar in terms of bringing about a paradigm shift in how we think about language and languages is in the public conversation. Not embedded in a particular educational institution, the independent scholar can reach out, not only to educators and academics, but to parents, communities, the media, and the creative world of the arts and literature, with the goal of creating interest and motivation in language learning among individuals and groups for whom language learning and use may not have been an area of interest or attention.

The independent scholar is ideally situated to build bridges between foreign language education and international/global education, within heritage language communities, or in working with socio-cultural organizations in bringing events, festivals, theater, and concert performances in other languages or highlighting other cultures. The independent scholar can seek out writing and research partners across the disciplines to examine virtually any issue or question through the lens of another language or culture, or publish in an international journal or even in another language. In addition, the independent scholar can write a newspaper piece, participate in a podcast, or make a television or radio appearance in a broader variety of venues, without going through the sometimes cumbersome approval process needed by embedded teachers and scholars, or by other language professionals.

More than 60M speak a language other than English in the home, the United States is a nation of immigrants, and the demand for foreign language skills and cultural knowledge exceeds supply in the US workplace, yet paradoxically, relatively few US students -- just under $20 \%$ of K-12 students, and only $7.5 \%$ of college and university students -- study another language (New American Economy, 2017; ACTFL, 2019; Ryan, 2013; American Councils, 2017; MLA, 2019). Despite this gap between supply and demand, and just as the world is becoming more globalized and interconnected and as our society is becoming more multilingual, the opportunity to learn another language is actually decreasing, especially in our elementary schools, middle schools, and colleges and universities (AMACAD, 2017). The US foreign language deficit has long impacted not only our economic and national security and our lives as global citizens, but also our ability to better understand, appreciate, and communicate those in our society and in our communities who speak other languages (Simon, 1982).

However, despite all evidence to the contrary, foreign language programs across the country and at all levels are at risk, in danger of cuts and possible elimination for a variety of reasons, ranging from budget shortfalls, curriculum changes, and a general decline in support for the humanities in US education, to a national shortage of qualified foreign language teachers.

For these reasons, advocacy for foreign language learning is needed, now more than ever, to promote interest in and study of other languages and to strengthen, support, and defend at-risk and endangered programs.

While educators, parents, and language stakeholders in business and government play key roles in foreign language advocacy, it is interesting to consider the role of the independent scholar. Able to turn their ability to establish a framework for the discussion of the benefits of foreign language learning and cultural knowledge, the independent scholar can examine these questions beyond the confines of a particular school, program, institution, or business or government entity, bringing their education and training to the conversation without any appearance of self-interest, or possibility of criticism from an employer. Often having more freedom as to where and how they publish than tenuretrack faculty, independent scholars can proactively seek out opportunities to publish research in multilingual journals, arrange for their work to be translated into other languages, and seek out research partners and co-authors from another 
culture and/or who write in another language. They can also speak out in support of language learning and language use in a broader array of settings that a K-12 teacher or tenure-track faculty member.

However, the most important factor may be the very nature of the independent scholar, who has chosen scholarship over a particular specific position or workplace. Having made that critical choice, driven by a core value of commitment to a specific area of scholarship, research, and writing, the independent scholar has not only more options for professional engagement and publication than a more traditional or embedded educator or scholar, but also a broader range of available action steps, including but not limited to social and political action. In addition, the independent scholar may often have the possibility of dedicating more time to advocacy, unburdened by the responsibilities and time constraints of a typical full-time faculty position. It is, indeed, this combination of scholarly education and training, value-driven engagement and relative freedom that make the independent scholar potentially the most powerful foreign language advocate. Combined with the relative ease of use and low cost of social media and a public conversation that favors discussion of issues in a wide range of settings, the American independent scholar can be considered a potential force for good, or change agent working for the greater good.

Accepting the potential of the independent scholar as a change agent for the greater good, in the spirit of social marketing, the next question concerns the development of an action plan that can be implemented locally or globally. In order to be an effective foreign language advocate, the independent scholar across the disciplines with an interest in languages, cultures, and intercultural communication and understanding must have an interest in advocacy, and that interest is a key factor. As advocacy is the subject of relatively few scholarly articles, and is found primarily in practitioner publications, many scholars may believe that advocacy is for others only. However, nothing could be farther from the truth, as scholars have the training, skills, and knowledge needed to actually develop and implement an effective foreign language advocacy initiative. These steps toward an effective action plan are based on Livermore's model of cultural intelligence (Livermore, 2011).

The second step is to develop an advocacy skills set, knowledge apart from one's particular scholarly area consisting of data on the current status of languages in the US, on their importance and benefits, and on programs, methods, and initiatives likely to increase interest and motivation. The third step is to develop one's own individual strategic plan, with short-, medium-, and longer-term goals as an advocate for foreign language learning and use. The fourth and final step is to take action, whether in person, through research and writing, or through social and online media, to create sustainable interest in other languages and cultures, and this action can be scholarly and academic, practitioner-oriented, or political and social.

Key questions that precede, accompany, and follow the development of an action plan for the independent scholar include time, expense, opportunity cost, and whether or not advocacy is in alignment with the independent scholar's chosen vision and mission. Answers include the fact that time and opportunity cost are driven by the core values of the individual, and financial expense can range from minimal to considerable, with an array of options available at all levels. However, the answer as to whether advocacy is in alignment with the one's vision and mission is both personal and objective, based on the data surrounding the current status of languages in the US and the goals of the independent scholar. Here, too, the independent scholar may be a more readily proactive advocate than a traditional educator or language professional in that the independent scholar is precisely that, independent from a traditional academic career path, and its obligations, able to act more individualistically and creatively.

\section{The IndePendent Scholar-Advocate -- Agility, Online Communities, Goals, Partnerships, And SkiLls}

Once convinced of this solidarity imperative of social responsibility, the independent scholar can proceed to build the advocacy skills needed the determined goals and objectives. Just as the path to cultural intelligence consists of 4 steps - interest, knowledge, strategy, and action (Livermore, 2011), so too does the path to advocacy. With interest and motivation firmly established, it is important that the independent scholar-advocate develop the necessary knowledge base both about advocacy methods, but also about the issues beyond scholarship itself impacting communities and the broader society in relation to the advocacy area and goals. It is also important to have a plan, with short- and longerterm goals, action steps to achieve them, and a timeline in order to measure progress and to stay on track. Lastly, it is important to take action, as the most knowledgeable individual with the best plan achieves little without taking action. Action steps need to be doable, and serving as benchmarks to measure success.

In his classic article, (Bhide, 1986) described the nature, role, and importance of "hustle as strategy," driven by vision executed with energy, resourcefulness, and professionalism. This defines the role of the independent scholar in foreign language advocacy. While all institutions, including educational institutions, are driven by sometimes cumbersome strategic plans, with innumerable goals, objectives, etc., the independent scholar, driven by his/her vision of the importance of language and languages, can move with agility to participate in and to shape the public conversation of foreign language learning and use

Agility, generally considered to be the ability to think, understand, and move quickly, is an essential part of the advocacy skill set. Educational institutions, while worthy in themselves, are bound by the structure, processes, and organizational factors inherent to all institutions. While these can serve many positive purposes, they can also limit and slow down the action of the advocate as change agent. Independent scholars, on the other hand, inherently enjoy 
considerably more freedom from these constraints, and can both quickly understand a rapidly evolving situation and act quickly to effectively address and even resolve it.

While it is often said that every revolution begins with one person, it is equally true that often "it takes a village." or community effort. While community often refers to a school, school district, or campus, it can refer to the increasingly important concept of an online community, which can support and encourage advocacy and change, whether social media post, an online petition, or a virtual organization and/or conference. Again, in this virtual environment, the independent scholar, who can be located anywhere, and is accustomed to working alone and often virtually, can unite effectively with like-minded enthusiasts and fellow change agents to participate in the public conversation through podcasts, be present through virtual meetings, and vote for change. The independent scholar, with relative freedom from a rigid schedule and organizational policies and politics, can act for change within a scholarly discipline or practice, or for broader social change across borders and time zones, and during times like the COVID-19 pandemic in 2020, when the need for online advocacy and change management are all the more important as the possibilities for travel and inperson meetings are dramatically diminished.

The goal of the independent scholar can be a short-term goal, to save an at-risk foreign language program, or to help to organize a cultural event, or it can be the long-term goal of effecting more fundamental change.

The question, as the value of education and of educational institutions is debated on a daily basis, is the manner in which the independent and the traditional, or embedded, scholar can and should work together. The broad questions include the role and value of education, and the responsibility of educators and scholars, and while independent and traditional/embedded scholars share many of the same core knowledge and skills, the value of collaboration among those who are embedded in academia, whether in postsecondary or in K-12 settings, with intentional outsiders may be a topic for discussion.

However, when faced with an issue for which they would like to advocate, an independent scholar may believe that he/she does not have the necessary skills or knowledge. Nothing could be further from the truth. An independent scholar has the research skills and dedication needed for advocacy, easily enhanced by learning the advocacy skills set, or core competencies. This skill set includes some skills needed by all advocates, and others may be more particularly suited to a particular discipline, advocacy project or goal, or a particular individual. While the advocacy skills set may be similar for all advocates, and especially, for all foreign language advocate, independent scholars play a unique role in that they can bridge the gap between K-12 and postsecondary educators, between scholars and educators embedded in careers in educational institutions and parents and community activists, and between educators and language specialists in business and government.

Advocates can attend in-person meetings and events and meet face-to-face with public officials and other decisionmakers, advocate through online and social media -- web pages, blogs, Facebook, Twitter, podcasts, etc., or adopt a blended, hybrid approach using the most effective tool for the task at hand. However, in order to be effective, each conversation, whether virtual or face-to-face, takes place within the framework of a particular advocacy strategy or method.

Advocacy questions can be framed by theory and best practices in change management, social marketing (not to be confused with social media), and disruptive innovation. Change management has been defined as an 8-step process beginning with the creation of "a sense of urgency" (Kotter, 2008). In the case of foreign language advocacy, the situation is indeed urgent, with a decline in opportunity for foreign language learning and a shortage of qualified foreign language teachers just as a globalized and interconnected world and the US workplace demand more language skills and cultural knowledge. Not to be confused with social media marketing, although it may use social media, social marketing, or using the strategies and tactics of marketing for the greater good, is an effective strategy for independent scholars, passionate about their research, to maximize its impact in terms of social relevance (Lee \& Kotler, 2019). As making the case for languages and persuading decision-makers of the importance of language learning is a major task of foreign languages advocates, the psychology of persuasion, which includes six principles -- including scarcity (just think of the gap between the supply of and demand for foreign language skills in the US workplace) -- is an valuable tool. (Cialdini, 2006).

Disruptive innovation is especially intriguing in that it changes, or disrupts, an existing product, service, and market through the development of a new product or service, often by outsiders (Christensen, 2013). In terms of foreign language learning and use, immersion programs, independent online learning platforms, heritage languages, and international/interdisciplinary education are among the current and potential disruptors. Immersion programs, with their exponential growth and demonstrated appeal among a broader public, are especially likely to change both foreign language education in the elementary and middle schools, and also college programs as large numbers of proficient and even fluent students reach college age, ready to deploy their language skills and cultural knowledge through interdisciplinary programs including and beyond STEM and business, international education, and language use within their communities and in our society.

Blue ocean strategy (Kim \& Mauborgne, 2015), which is grounded in the development of new markets through the creation of a new, better, or less expensive product or service, can be viewed in foreign language learning from the perspective of public school immersion programs, which increase accessibility of language and cultural learning through the use of more than one language as the medium of instruction, beginning with the earliest grades. 
However, at times even the best arguments remain unheard due to a myriad of social, political, and economic factors. At that time, while many language advocates may prefer the scholarly conversation, the effective advocate needs to be willing and able to move to the next stage of the advocacy conversation, which can include negotiation, confrontation, lobbying, and even protest and social movements. While all of these have certain elements in common, their focus is different, with an emphasis of a win-win solution in negotiation Fisher, Ury, \& Patton, 2011), a willingness to potentially engage in direct confrontation with authority, lobbying involving persuasion and grassroots political action, and protest (Satell \& Popovic, 2017) involving a readiness to engage in direct social action to achieve the goal.

\section{Challenges to The IndePendent ScholaR as Foreign Language Advocate}

However, these very advantages that the independent scholar can bring to advocacy for a cause, for a paradigm shift, for example, in the ways that Americans typically view the learning and use of additional languages, can also be disadvantages in that the independent scholar may be perceived as a non-expert, a non-academic, or simply as an outsider. To overcome this potential challenge, an effective advocate and change agent, including the independent scholar, needs to consistently engage with other foreign language stakeholders, to support foreign language learning initiatives and campaigns, and to serve the cause without any appearance of self-interest. Overall, the strengths of the independent scholar-advocate in terms of motivation, resourcefulness, skills, and freedom, far outweigh the challenges.

\section{CONCLUSIONS}

Foreign language learning is at a critical point in time in the US., where opportunities for language learning are not universally available and are, in fact, decreasing. On the one hand, however, more Americans than ever before speak languages other than English in the home, and in addition, many English-speaking parents would like their children to enjoy the academic, cognitive, personal, and professional benefits of bilingualism. Many Americans of all ages are interested in learning other languages -- either a heritage language, the language of a loved one, a language that would bring career advancement or increased employability, or a language that they are interested for any number of other reasons. The conversation about language learning and use in the US is at a "tipping point" (Gladwell, 2000), or watershed moment, where foreign language advocacy -- whether through large national, regional, and state campaigns, or through both strategic and vigorous (Bhide, 1986) action by motivated individuals -- can make a difference, creating a paradigm shift in foreign language learning and use.

In order to bring about the much-needed paradigm shift in foreign language learning (Jaumont \& Stein-Smith, 2019) and use in the United States, advocacy is needed, and who better than independent scholars, free from the constraints often found among traditional scholars and educators embedded in schools and universities? Pursuing their research, writing, and engagement with expertise and passion, but most importantly, outside of academia, and accustomed to the time management and other challenges of juggling scholarly research, writing, and engagement, with non-academic careers, independent scholars are ideally situated to play a critical role in foreign language advocacy as public intellectuals.

As intentional outsiders, independent scholars have not only the skills, resourcefulness, and relative freedom needed, but also the responsibility to engage in advocacy without self-interest, in solidarity for the greater good, and even with altruism. The case of the independent scholar-advocate as change agent can be generalized to include advocacy for the greater good in many areas of our society.

\section{REFERENCES}

[1] American Academy of Arts and Sciences (AMACAD). Commission on Language Learning (2017). America's Languages: Investing in Language Education for the 21st Century 02/2017 https://www.amacad.org/publication/americas-languages (Accessed 20/04/2020).

[2] American Association of Teachers of French (AATF). Commissions. https://frenchteachers.org/about/commissions/ (Accessed 20/04/2020).

[3] American Council on the Teaching of Foreign Languages (ACTFL). (2019). Making Languages Our Business: Addressing Foreign Language Demand among U.S. Employers. https://www.actfl.org/news/reports/making-languages-our-businessaddressing-foreign-language-demand-among-us-employers (Accessed 20/04/2020).

[4] America Counts Staff (2019). Number of People with Master's and Doctoral Degrees Doubles since 2000. 21/02/2019 https://www.census.gov/library/stories/2019/02/number-of-people-with-masters-and-phd-degrees-double-since-2000.html (Accessed 20/04/2020).

[5] American Council on the Teaching of Foreign Languages. (2019). Making Languages Our Business: Addressing Foreign Language Demand among U.S. Employers. https://www.leadwithlanguages.org/language-advocacy/publications/ (Accessed 20/04/2020).

[6] American Councils on International Education. (2017). The National K-12 Foreign Language Enrollment Survey Report. 31/05/2017 https://www.americancouncils.org/news/announcements/new-report-world-language-study-us-k-12-schools (Accessed 20/04/2020).

[7] American Academy of Arts and Sciences (AMACAD). Commission on Language Learning (2017). America's Languages: Investing in Language Education for the 21st Century 02/2017 https://www.amacad.org/publication/americas-languages (Accessed 20/04/2020). 
[8] Bhide, A. (1986). Hustle as Strategy. Harvard Business Review https://hbr.org/1986/09/hustle-as-strategy (Accessed 20/04/2020).

[9] Cialdini, J. (2006). Influence: The Psychology of Persuasion, rev. ed. New York: Harper Business.

[10] Christensen, C.M. (2013). The Innovator's Dilemma: When New Technologies Cause Great Firms to Fail. (reprinted) Brighton, MA: Harvard Business Review Press.

[11] Daly, J. (2011). Advocacy: Championing Ideas and Influencing Others. New Haven, CT: Yale.

[12] Devlin, K. (2015). Learning a foreign language a 'must' in Europe, not so in America. 13/07/2015 https://www.pewresearch.org/fact-tank/2015/07/13/learning-a-foreign-language-a-must-in-europe-not-so-in-america/ (Accessed 20/04/2020).

[13] Devlin, K. (2018). Most European Students Are Learning a Foreign Language while Americans Lag. 06/08/2018 https://www.pewresearch.org/fact-tank/2018/08/06/most-european-students-are-learning-a-foreign-language-in-school-whileamericans-lag/ (Accessed 20/04/2020).

[14] Fisher, R., Ury, W. L, and Patton, B. (2011). Getting to Yes: negotiating Agreement without Giving In. rev. exp. ed. NY: Penguin.

[15] Grosjean, F. (2010, 2020). Bilingualism's best-kept secret: More than half of the world's population is bilingual. https://www.psychologytoday.com/us/blog/life-bilingual/201011/bilingualisms-best-kept-secret Accessed 13/04/2020. (Accessed 20/04/2020).

[16] Gross, R. (1982). The Independent Scholar's Handbook. Reading, MA: Addison-Wesley.

[17] Hutt, R. (2019). Which Countries Have the Most Doctoral Graduates? 15/10/2019. https://www.weforum.org/agenda/2019/10/doctoral-graduates-phd-tertiary-education/ (Accessed 20/04/2020).

[18] Jaumont, F. \& Stein-Smith, K. (2019). The Gift of Languages: Paradigm Shift in U.S. Foreign Language Education. NY: TBR.

[19] Kim, W. C., and Mauborgne, R. (2015). Blue Ocean Strategy, Expanded Edition: How to Create Uncontested Market Space and Make the Competition Irrelevant Brighton, MA: Harvard Business Review Press.

[20] King, M. L., Jr. (1947). The Purpose of Education. https://kinginstitute.stanford.edu/king-papers/documents/purpose-education (Accessed 20/04/2020).

[21] Kotter, J. (2008). A Sense of Urgency. Brighton, MA: Harvard Business Press.

[22] Lee, N.R., and Kotler, P. (2019). Social Marketing: Behavior Change for Social Good 6th ed. Thousand Oaks, CA: SAGE.

[23] Livermore, David. (2011). The Cultural Intelligence Difference: Master the One Skill You Can't Do Without in Today's Economy. NY: AMACOM.

[24] McComb, C. (2001). About One in Four Americans Can Hold a Conversation in Another Language. https://news.gallup.com/poll/1825/about-one-four-americans-can-hold-conversation-second-language.aspx (Accessed 20/04/2020)

[25] Merriam-Webster. Dictionary. https://www.merriam-webster.com/dictionary/advocacy (Accessed 20/04/2020).

[26] Merriam-Webster. Dictionary. n.d. https://www.merriam-webster.com/dictionary/education (Accessed 20/04/2020).

[27] Modern Language Association (MLA) (2019). Enrollments in Languages Other Than English in United States Institutions of Higher Education. https://www.mla.org/Resources/Research/Surveys-Reports-and-Other-Documents/Teaching-Enrollmentsand-Programs/Enrollments-in-Languages-Other-Than-English-in-United-States-Institutions-of-Higher-Education (Accessed 20/04/2020).

[28] National Education Association (NEA). (2019). An Educator's Guide to the "Four Cs": Preparing 21st Century Students for a Global Society. http://www.nea.org/tools/52217.htm (Accessed 19/05/2020).

[29] New American Economy. (2017). Not Lost in Translation: The Growing Importance of Foreign Language Skills in the U.S. Job Market. https://research.newamericaneconomy.org/report/not-lost-in-translation-the-growing-importance-of-foreign-languageskills-in-the-u-s-job-market/ (Accessed 20/04/2020).

[30] Ratcliffe, S., ed. (2017). Oxford Essential Quotations, 5th ed. https://www.oxfordreference.com/view/10.1093/acref/9780191843730.001.0001/q-oro-ed5-00007046 (Accessed 20/04/2020).

[31] Ryan, C. (2013). Language Use in America: 2011. https://www2.census.gov/library/publications/2013/acs/acs-22/acs-22.pdf (Accessed 20/04/2020).

[32] Satell, G. \& Popovic, S. (2017). How Protests Become Successful Social Movements. Harvard Business Review https://hbr.org/2017/01/how-protests-become-successful-social-movements (Accessed 20/04/2020).

[33] Simon, P. (1982). The Tongue-Tied American: Confronting the Foreign Language Crisis. NY: Continuum.

[34] Stein-Smith, K. (2019). Foreign language classes becoming more scarce. 06/02/2019 https://theconversation.com/foreignlanguage-classes-becoming-more-scarce-102235 (Accessed 20/04/2020).

[35] Union Institute \& University (UI\&U). (2020). Our Mission. https://myunion.edu/about-union/mission-and-values (Accessed $19 / 05 / 2020$.

[36] United Nations Development Programme (UNDP). (2020).Sustainable Development Goals. n.d. https://www.undp.org/content/undp/en/home/sustainable-development-goals.html (Accessed 20/04/2020).

[37] U.S. Department of Education (USDOE). (2015). Make the World a Better Place. 02/05/2015. https://www.ed.gov/news/speeches/make-world-better-place (Accessed 20/04/2020).

[38] Wilson, R. (2017). Census: More Americans have college degrees than ever before. 03/04/2017. https://thehill.com/homenews/state-watch/326995-census-more-americans-have-college-degrees-than-ever-before (Accessed 20/04/2020). 


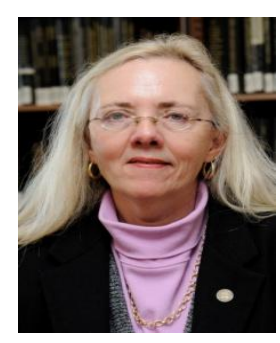

Matters."

Kathleen Stein-Smith, $\mathrm{PhD}$, Chevalier dans l'Ordre des Palmes académiques, is a dedicated foreign language educator and advocate.

She is Chair of the AATF (American Association of Teachers of French) Commission on Advocacy and a member of the ATA Education and Pedagogy Committee. She is also active in foreign language education associations, including the NECTFL Advisory Council, CSCTFL Advisory Council, and as a SCOLT sponsor. She is Communications Officer of the NCIS (National Coalition of Independent Scholars).

She has presented at numerous professional conferences at the state, regional, and national level, is the author of four books and numerous articles about the foreign language deficit, has given a TEDx talk on The U.S. foreign language deficit, has been interviewed by press and radio, and maintains a blog, "Language 